Research Papers, part of a Special Feature on Conservation of Grassland Birds: Causes and Consequences of Population Declines

\title{
Mortality of Parental Mountain Plovers (Charadrius montanus) during the Post-hatching Stage.
}

\section{Mortalité adulte des Pluviers montagnards (Charadrius montanus) pendant la période d'élevage des jeunes}

\author{
Victoria J. Dreitz $^{1}$
}

\begin{abstract}
Monitoring, management, and conservation of grassland birds are topics of importance because of widespread population declines. Annual estimates of survival are available for many species, however knowledge of how survival varies on a seasonal basis remains poor. Information on the relative effects of breeding, overwintering, and migratory periods on population dynamics is necessary for effective management. Mortality risks often vary with the stage of the breeding cycle. In precocial species, mortality risks of adult birds are often higher during post-hatching care than prehatching. Using a multistate modeling approach, I investigated the influence of both environmental characteristics, measured by habitat, and individual characteristics, measured by sex and body mass, on post-hatching parental mortality of a declining grassland species, the Mountain Plover (Charadrius montanus). I found minimal evidence to support the effect of habitat, sex, or body mass on post-hatching parental mortality. Daily parental mortality was 0.0037 $(\mathrm{SE}=0.0007, \mathrm{CI}=0.0026,0.0053)$ and survival during the 30 -day post-hatching period was 0.8943 (SE $=0.0187, \mathrm{CI}=0.8512,0.9255)$. The findings from this study provide an understanding of the associations with today's grassland habitats and the dynamics of Mountain Plovers during the breeding season. Prior to assessing if alterations in habitats are acting more on post-hatching than the other stages of the annual cycle for the Mountain Plover, information on survival during other breeding stages and during migration is needed to assist in developing effective conservation and management plans.
\end{abstract}

RÉSUMÉ. Le suivi, la gestion et la conservation des oiseaux de prairie ont une grande importance étant donné le déclin des populations qui sévit à grande échelle. Les estimations annuelles du taux de survie sont connues pour de nombreuses espèces, mais la variation de ce taux en fonction des saisons l'est peu. Il est important de connaître les effets relatifs de la période de reproduction, d'hivernage ou de migration sur la dynamique des populations afin de gérer adéquatement les populations. Ainsi, le risque de mortalité varie souvent selon l'étape au cours de la reproduction. Chez les espèces nidifuges, le risque de mortalité des adultes est habituellement plus élevé pendant l'élevage des jeunes qu'avant l'éclosion. Au moyen d'une approche de modélisation multi-états, les caractéristiques environnementales, mesurées grâce à l'habitat, et les caractéristiques individuelles, mesurées à partir du sexe et de la masse corporelle, ont été testées pour voir si elles avaient de l'influence sur la mortalité des adultes au moment de l'élevage des jeunes, chez le Pluvier montagnard (Charadrius montanus), oiseau de prairie en déclin. Seuls des effets très faibles de l'habitat, du sexe et de la masse corporelle sur la mortalité des adultes en période d'élevage ont été trouvés. La mortalité quotidienne des adultes était de 0,0037 (erreur-type $=0,0007$; IC $=0,0026$ et 0,0053 ) et le taux de survie durant la période d'élevage de 30 jours était de 0,8943 (erreur-type $=0,0187$; IC $=0,8512$ et 0,9255 ). Les données issues de cette étude permettent de comprendre le lien qui existe entre les milieux de prairie actuels et la dynamique du Pluvier montagnard durant la saison de reproduction. Avant de pouvoir

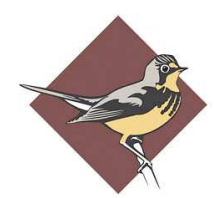

BIRD STUDIES CANADA 
évaluer si les changements survenus dans l'habitat ont davantage d'effets en période d'élevage qu'au cours des autres étapes du cycle annuel du Pluvier montagnard, l'évaluation du taux de survie durant les autres étapes de la reproduction et pendant la migration est requise si on veut établir des plans de gestion et de conservation efficaces.

Key Words: adult survival; Charadrius montanus; Colorado, USA; Mountain Plover; post-hatching care; precocial species

\section{INTRODUCTION}

The distribution and abundance of migratory birds are limited by processes occurring throughout their annual cycle with events during one stage of the cycle influencing the population in subsequent stages. To manage migratory birds, we need to understand the relative effects of breeding, overwintering, and migratory periods on population dynamics. Knowledge of how survival varies on a seasonal basis is lacking for most species with the exception of studies largely focusing on waterfowl (e.g., Blohm et al. 1987, Owen and Black 1991, Ward et al. 1997, Gauthier et al. 2001, Madsen 2002, Bond et al. 2009). Seasonal survival estimates are needed to elucidate the processes that determine distribution and abundance for developing management and conservation plans.

The exposure to mortality risks often varies with respect to the stage of the breeding cycle. Prior to incubation, birds engage in a variety of activities including courtship, feeding, searching for nest sites, nest construction, and egg production. Incubating individuals must balance the competing demands of maintaining good physical condition while keeping an optimum nest environment for developing eggs including fending off predators. After incubation, successful adults are faced with the challenge of caring for young. Parental care of precocial species is generally considered less demanding than raising altricial young because most precocial young forage on their own immediately or shortly after hatching, easing energy demands on parent(s). In some precocial species, the mortality risk of post-hatching care, including brooding and defending young, is lower than other stages of the breeding season (e.g., Hartke et al. 2006, Hagen et al. 2007). However, it has been suggested that for some precocial species, mortality risks of post-hatching care may be higher than prehatching care (Owens and Bennett 1994, Liker and Székely 2005). The discrepancy among precocial species as to when the highest risk of mortality occurs during the breeding season may be an artifact of differences in predator communities.

I investigated the rate of adult mortality during the post-hatching period on a declining population of grassland species, the Mountain Plover(Charadrius montanus). The Mountain Plover is an upland precocial bird that breeds throughout the prairie ecosystems of the North America Great Plains. The Great Plains region has been greatly altered from expansive and diverse prairie ecosystems into small habitat patches of homogenous grasslands interspersed with agricultural lands (Smith and Lomolino 2004). The grasslands and agricultural fields of the eastern plains of Colorado provide breeding habitat for over half of the continental population of Mountain Plover (Knopf and Rupert 1999, Dreitz and Knopf 2007, Dreitz 2009, Tipton et al. 2009) and smaller, more isolated breeding areas occur throughout the western Great Plains region (Knopf and Wunder 2006). I hypothesized that mortality of post-hatching parental Mountain Plovers may be influenced by: (1) different habitats and the associated movement patterns among habitats, and (2) condition of the parent, as measured by its physical characteristics.

Parental mortality risks may vary with changes in habitat use during the post-hatching period. Adults move young to different habitats to better protect themselves and their young from predators (Lengyel 2006), or to exploit better foraging resources (Johannson and Blomqvist 1996, Pearce-Higgins and Yalden 2004). Mountain Plovers are capable of leading their chicks from the nest site up to $2 \mathrm{~km}$ within two days of hatching (Knopf and Rupert 1999). Movement of adults with young may entail moving through different habitat types (Knopf and Rupert 1999, Dreitz et al. 2005, Dreitz 2009). The survival of Mountain Plover chicks can vary among 
habitats (Dreitz 2009). Whether this pattern is the result of the death of parental adults is unknown.

Mortality risks of post-hatching parental adults may also differ between the sex of the tending parent or vary with body condition. Mountain Plovers breeding behavior is one of the more unusual in shorebirds in which each adult of a pair tends singly to a clutch until the young fledge (Graul 1973). In other shorebirds species, mortality risks for males are greater than females because males approach predators more closely and exhibit more intensive distraction behavior (Brunton 1990, Székely 1996). In species where body mass differs between males and females, the sex with the lower mass may have lower energetic reserves, and thus, is more vulnerable to mortality risks.

Conservation efforts require reliable information on habitat associations to reverse the continental-scale declines of grassland birds over the past century (Askins et al.2007 and references within). Increased mortality rates of post-hatching parental Mountain Plovers among habitats may decrease reproductive success to the extent that compromised parental care constitutes a heightened conservation problem. Here, I estimate and compare the mortality rate of post-hatching parental, hereafter, simply parental, Mountain Plovers on three breeding habitats; agricultural fields, native grassland not occupied by black-tailed prairie dogs (Cynomys ludovicianus), and grassland occupied by black-tailed prairie dogs. I include sex of the tending adult and body mass near or at hatching to determine if individual characteristics influence mortality rates. I use a multistate modeling approach to account for how movement from one habitat to a different habitat influences parental mortality. The study presented in this paper is one of the first analyses investigating factors influencing parental survival during posthatching on Mountain Plovers.

\section{METHODS}

\section{Study area and field methods}

The three-year study was conducted from 2004 to 2006 in the central eastern plains of Colorado, USA $\left(36^{\circ} 59^{\prime} \mathrm{N}-39^{\circ} 00^{\prime} \mathrm{N}, 102^{\circ} 02^{\prime} \mathrm{W}-104^{\circ} 00^{\prime} \mathrm{W}\right)$ on approximately $21,500 \mathrm{~km}^{2}$ of privately owned lands. The landscape is relatively flat, arid, and primarily dominated by shortgrass prairie and dryland agricultural fields. Shortgrass prairie was primarily vegetated by buffalograss (Buchloe dactyloides) and blue grama (Bouteloua gracilis), and grazed to varying degrees by cattle, hereafter, simply grassland, and black-tailed prairie dogs, hereafter, simply prairie dog. Agricultural fields were comprised of dryland cereal crops (e.g., wheat, sorghum) and fallow fields with varying structure of dryland crop stubble. Specific field sites were selected such that a habitat was $<2 \mathrm{~km}$ from one of the other two habitats to permit movements between habitats. Boundaries distinguishing agricultural fields from the other habitats were easy to determine visually. When adjacent to grassland, prairie dog habitat was defined as the prairie dog colony plus a $0.40 \mathrm{~km}$ buffer based on similarities in vegetative structure, e.g., height, amount of bare ground (Dreitz 2009). The total area of each habitat included in the study was approximately the same for agricultural and prairie dog habitat but greater for grassland habitat. In the study area, Mountain Plovers start their breeding cycle with egg-laying in mid-April (Graul 1975) and fledging of young occurs through July and perhaps longer (Knopf and Wunder 2006). Field seasons generally lasted from mid-April to early-August.

Adult plovers were captured with a walk-in trap placed over the nest one to five days prior to hatching date. They were weighed and a $1.8 \mathrm{~g}$ radio transmitter (model A2450, Advanced Telemetry Systems, Isanti, Minnesota) was glued to nesttending adults. Transmitters were affixed by applying a light coating of waterproof epoxy and sliding it under the upper layer of mantle feathers so that the transmitter was positioned between feathers (Dreitz et al. 2005, Dreitz 2009). The procedure enables the transmitters to shed when the birds molted prior to their fall migration. Battery life of transmitters was expected to be $\geq 56$ days. A US Geological Survey numbered metal band and region-specific colored plastic band was placed on the adults, and a feather sample was collected for sex determination by DNA analysis (Avian Biotech, Tallahassee, Florida).

After hatching, the adults were located every 24 to 48 hours to record their location, habitat, and if chicks were present. Adults were located at distances $\geq 500 \mathrm{~m}$ to prevent forcing movements caused by investigator disturbance. If vegetation or topography prevented sightings, observers decreased their distance to the bird to confirm observation or modify as necessary. The sample approaching was repeated until chicks were 30 days post-hatch. 
Adults that lost their brood, as confirmed by locating carcasses of chicks, left the study area within five days after their brood was lost (V. J. Dreitz, unpublished data).

\section{Statistical analysis}

A multistate, also known as multistrata, modeling approach was used to investigate the daily rate of mortality of parental Mountain Plovers. The multistate approach is an extension of the CormackJolly-Seber (Cormack 1964, Jolly 1965, Seber 1965) live captures model extended to multiple states or strata (Hestbeck et al. 1991, Brownie et al. 1993, Schwarz et al 1993). The premise of the multistate model is based on the idea that each individual at time $t+1$ is in a 'state', and that 'state' is a stochastic function of its 'state' at time $t$. Animals either remain in a given state, e.g., survive and stay in a given area, or transition to a different state, e.g., survive and move to a different area. States can be any discrete variable such as geographic areas, physiological states, e.g., age or weight, or behavioral status, e.g., breeding or nonbreeding.

The classical framework of the multistate approach permits simultaneous estimate of survival, $\Phi_{i}^{S}$, probability that an individual survives the time interval $i$ to $i+1$ if in state $s(s=1, \ldots . k)$ at time $i$ and remains available for detection at $i+1$; detection probability, $p_{i}^{s}$, is the probability of detection at time $i$ for an individual in state $s$ at time $i$; and the transition matrix, $p s i i_{i}^{r s}$, is the probability that an individual in state $r$ moves to state $s$ at the end of the interval starting at time $i$, conditional on the individual remaining alive and available for detection. However, when dealing with both live resightings and dead recoveries occurring on a state, survival must be moved to a transition matrix where it appears as a transition from the state 'alive' to the state 'newly dead' (Lebreton et al. 1999, Duriez et al 2009). The same idea applies when having several states resulting in multiple survival and movement probabilities in the transition matrix.

The multistate approach used for this study is similar to Duriez et al. (2009) in that it allows for simultaneous estimation of mortality and movement between habitats using data based on live resighting and dead recoveries. There were six potential states in this study: alive on agricultural fields (AG), dead on agricultural fields (ag), alive on prairie dog (PD), dead on prairie dog (pd), alive on grassland (GR), or dead on grassland (gr; Fig. 1). Thus, there are a total of 18 possible transitions. Reverse transitions are allowed for live adults but not for dead adults. The parameterization of the multistate model for this study follows:

- $\Phi_{x}=$ fidelity $=$ probability of parental adult staying in the study area (no permanent emigration) given the adult had young on habitat $x$, where $x \in$ \{agricultural fields, prairie dog colonies, grassland $\}$,

- $\quad p_{s}=$ detection $=$ probability of resighting adults of status $s$, where $s \in\{$ live, dead ,

- $\Psi_{x(l) \rightarrow y(l)}=$ movement $=$ conditional probability of transition from a live state $(l)$ on habitat $x$ at $t$ to a live state $(l)$ on habitat $y$ at $t+1$, where $x$ or $y \in$ agricultural fields, prairie dog colonies, grassland $\}$ for $x=y$ or $x$ $\neq y$,

- $\Psi_{x(l) \rightarrow y(d)}=$ mortality = conditional probability of transition from a live state $(l)$ on habitat $x$ at $t$ to a dead state $(d)$ on habitat $x$ or $y$ at $t+1$, where $x$ or $y \in$ agricultural fields, prairie dog colonies, grassland $\}$ for $x$ $=y$ or $x \neq y$.

Unlike Duriez et al. (2009), I used the notation for mortality (or 1-survival) as $\Psi_{x(l)} \rightarrow_{y(d)}$ to show the estimation for this parameter occurred in the transition matrix versus using the traditional notation for survival, $\Phi$. The defined parameters are used to model the events giving rise to various encounter histories and assessed environmental and individual effects on parental mortality, movement, and detection, or resighting, probabilities. The multistate analysis was conducted in program MARK (White and Burnham 1999) using the Multistrata Live Encounters data type. The strata were coded as follows: live on agricultural fields (A), dead on agricultural fields (a), alive on grassland (B), dead on grassland (b), live on prairie $\operatorname{dog}(\mathrm{C})$, dead on prairie dog (c); " 0 " represents a sampled but undetected adult, and "." represents a sampling occasion in which the adult was not sampled. Sampling occasions were daily time steps spanning the 30 day post-hatching period. Another variant of this multistate analysis from Duriez et al. (2009) is the inclusion of data from animals that are 
Fig. 1. Conceptual framework showing the different states of adult Mountain Plovers (Charadrius montanus) during brood-rearing on three habitats. The figure only shows movement to a different state. Staying in the same state is not shown. Dashed lines represent mortality events and solid lines represent movement of an individual to a different habitat. A live state is represented by "l" and dead state by "d". Agricultural fields are represented by "AG" with red arrows denoting movement off this habitat, "PD" represents grassland occupied by prairie dogs with blue arrows denoting movement off this habitat, and "GR" represents grassland not occupied by prairie dogs with green arrows denoting movement off this habitat.

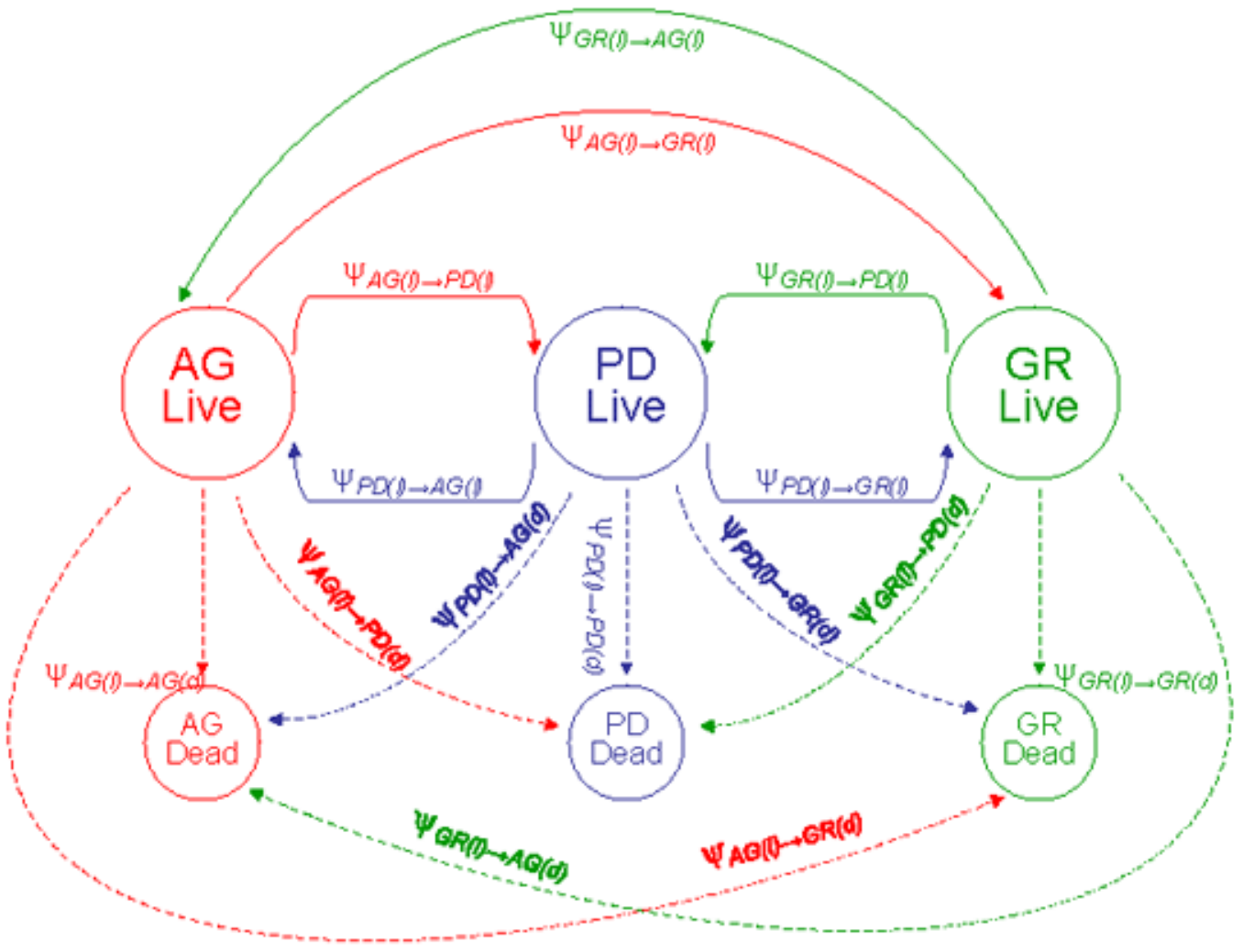

not sampled, ".". For example, with 10 sampling occasions, an encounter history for program MARK of a dead bird would be:

\section{AC.0Cb... 101101.5}

On the first sampling occasion, the parent was initially observed alive on agricultural fields. It moved to and was resighted alive on prairie dog habitat during the second occasion, was not sampled during the third occasion, was sampled but not resighted during the fourth occasion, was resighted alive on prairie dog habitat during the fifth occasion, was recovered dead on grassland during the sixth occasion. It was not sampled thereafter. The first ' 1 ' is the frequency of individual birds with this encounter history. The ' 0 ' represents the adult was not a male, and the second ' 1 ' represents the adult was a female. That is, there were three potential covariates for sex of the adult: male, female, and unknown. The value ' 101.5 ' is the body mass when the transmitter was placed on the adult. An example of a live bird at the end of the 10 sampling occasions is:

\section{AAA..COCCC 10099.8}

The individual was initially observed alive on sampling occasion 1 on agricultural fields, was resighted alive on agricultural fields during 
occasions 2 and 3 , was not sampled during occasions 4 and 5, was resighted alive on prairie dog habitat during occasion 6 , was sampled but not observed during sampling occasion 7 , was resighted alive and on prairie dog habitat on occasions 8,9 , and 10 . The first ' 1 ' represents the number of birds with this encounter history. The two ' 0 's represent the sex of the adult could not be determined and ' 99.8 ' is the body mass. An example of a bird in which the fate at the end of the 10 sampling occasions is unknown, e.g., bird was not located dead or alive, is:

\section{CCCO.C000011095.8}

The individual was initially observed alive on sampling occasion 1 on prairie dog habitat, was resighted alive on prairie dog habitat on occasions 2 and 3, was sampled but not observed on sampling occasion 4, was not sampled on sampling occasion 5 , was resighted alive on prairie dog on occasion 6 , was sampled but not observed during occasions 7 , 8,9 , and 10 . The first ' 1 ' represents the number of birds with this encounter history. The second ' 1 ' represents the adult was a male, the ' 0 ' represents the adult was not a female and ' 95.8 ' is the body mass. Lastly, an example of a bird in which the radio transmitter was found but the fate of the bird could not be confirmed ( $n=19$ adult) is:

\section{BBBB00.... -1 1097.2}

The parental adult was located alive on grassland on sampling occasions 1, 2, 3, and 4, was sampled but not observed on occasion 5 , the radio transmitter was recovered but the fate of the adult could not be determined, e.g., no evidence to confirm death or radio may of fallen off, on occasion 6 , then was not sampled for the remaining occasions. The frequencies for this adult is given a ' -1 ', to note the individual is censored. The ' 1 ' represents the adult was a male, the ' 0 ' represents the adult was not a female, and ' 97.2 ' is the body mass.

A set of candidate models was developed to examine individual and environmental effects on parental mortality. Fidelity, $\Phi_{x}$, was modeled as constant (.) for the study because parental adults are not likely to leave the study area with their chicks, given chicks are not capable of flight until $\geq 30$ days posthatch. If an adult does leave the study area, they likely lost their chicks, thus are no longer 'parental'. I chose a simple structure $p_{s}$ keeping it constant (.) for both live detections and dead recoveries. First, radio telemetry was used to locate parental adults; environmental factors such as habitat are unlikely to influence the ability to observe a live parent, $p_{\text {live }}$, or recover a dead parent, $p_{\text {dead }}$. Additionally, sampling factors such as year because of different observers each year of this study may influence $p_{\text {live }}$ but that would also influence $p_{\text {dead }}$ similarly. There were a low number of dead recoveries each year which would yield unstable estimates of $p_{\text {dead }}$. Brood movement patterns on the same three habitats suggest that if broods move off one of these habitats, they move at an equivalent rate to one of the other two habitats (Dreitz 2009). Therefore, for movement, $\Psi_{\mathrm{x}(\mathrm{l}) \rightarrow y(l)}$, I set the parameter of moving off a habitat to one of the other habitats equal, such that $\Psi_{\text {agfields }(l) \rightarrow \text { grassland }(l)}=\Psi_{\text {agfields }(l) \rightarrow \text { prairie } \operatorname{dog}(l)}$. I included no effect (.) and the effects of the sex of the tending adult (Sex) and habitat (Habitat) on $\Psi_{\mathrm{x}}$ (1) $\rightarrow y(t)$. I also allowed for an additive effect of habitat and sex (Habitat+Sex). These effects were also used for mortality, $\Psi_{\mathrm{x}(1) \rightarrow y(d)}$, plus the body mass of the parental adult at time of placement of radio transmitter. Body mass at time of placement of transmitter was included as a single effect and an additive effect with habitat (Habitat+Weight). A total of 12 models were developed for the analysis (Table 1).

A first step in model selection is to assess the goodness-of-fit of the model that assumes independent fate between past and present history of individual. Unlike Duriez et al. (2009), a direct goodness-of-fit test cannot be calculated because on some sampling occasions parental adults were not sampled. I used model selection criterion that follows the parsimony principle based on Akaike's Information Criterion (AIC; Akaike 1973, Burnham and Anderson 2002) adjusted for small samples sizes (AIC ; Hurvich and Tsai 1989). The models were ranked and compared in terms of their ability to explain variation in the empirical data using $\triangle \mathrm{AIC}_{\mathrm{c}}$ and $\mathrm{AIC}_{\mathrm{c}}$ weights (Burnham and Anderson 2002). The $\Delta A I C_{c}$ for a given model is the difference in $\mathrm{AIC}_{\mathrm{c}}$ between the best approximating model and all other models (Burnham and Anderson 2002). Further, to better interpret the relative likelihood of a given model over a set of models, models are normalized, by summing to 1 , to be a set of $\mathrm{AIC}_{\mathrm{c}}$ weights, $w_{i}$. Therefore, the larger the $\Delta \mathrm{AIC}_{\mathrm{c}}$, the smaller the $\mathrm{AIC}_{\mathrm{c}}$ weight, and the less plausible the given model. Multistate models have a potential to have multiple maximums in the likelihood function. To ensure the parameter estimates were the global maximum of the likelihood function, I used simulated annealing. 
Table 1. Summary of model selection results for mortality of Mountain Plover (Charadrius montanus) tending broods in the eastern plains of Colorado, USA, 2004-2006. Models presented in ascending order by Akaike's Information Criterion $\left(\mathrm{AIC}_{\mathrm{c}}\right)$, with $\triangle \mathrm{AIC}_{\mathrm{c}}$ indicating the difference between each model and the model with the lowest $\mathrm{AIC}_{\mathrm{c}}$ value and wi representing the $\mathrm{AIC}_{\mathrm{c}}$ weight and $\mathrm{K}$ the number of parameters in the model. ' + ' denotes the parameter had an additive effect of two covariates; '.' represents the parameter as held constant, 'habitat' varied by habitat type, 'sex' varied by sex of the adult, and 'weight' varied by weight of the adult at capture.

\begin{tabular}{|c|c|c|c|c|c|c|c|c|}
\hline \multirow[b]{2}{*}{ Fidelity } & \multicolumn{4}{|c|}{ Model } & \multirow[b]{2}{*}{$K$} & \multirow[b]{2}{*}{$\mathrm{AIC}_{\mathrm{c}}$} & \multirow[b]{2}{*}{$\Delta \mathrm{AIC}_{\mathrm{c}}$} & \multirow[b]{2}{*}{$w_{i}$} \\
\hline & Movement & Mortality & $\begin{array}{c}\text { Live } \\
\text { Recapture }\end{array}$ & $\begin{array}{c}\text { Dead } \\
\text { Recovery }\end{array}$ & & & & \\
\hline . & Habitat & . & . & . & 7 & 1888.02 & 0.00 & 0.54 \\
\hline . & Habitat + Sex & . & . & . & 8 & 1889.63 & 1.61 & 0.24 \\
\hline . & Habitat & Habitat & . & . & 9 & 1890.66 & 2.64 & 0.14 \\
\hline . & Habitat + Sex & Habitat + Sex & . & . & 11 & 1891.86 & 3.84 & 0.08 \\
\hline . & . & Sex & . & . & 6 & 1932.60 & 44.58 & 0.00 \\
\hline . & . & . & . & . & 5 & 1932.97 & 44.95 & 0.00 \\
\hline . & Sex & Sex & . & . & 7 & 1933.83 & 45.81 & 0.00 \\
\hline . & Sex & . & . & . & 6 & 1934.25 & 46.24 & 0.00 \\
\hline . & . & Weight & . & . & 6 & 1934.61 & 46.59 & 0.00 \\
\hline . & . & Habitat + Sex & . & . & 8 & 1935.24 & 47.22 & 0.00 \\
\hline . & . & Habitat & . & . & 7 & 1935.61 & 47.59 & 0.00 \\
\hline . & . & Habitat + Weight & . & . & 8 & 1937.26 & 49.24 & 0.00 \\
\hline
\end{tabular}

Additionally, I calculated parental survival for the 30-day post-hatching period as:

$$
S_{30 \text {-day }}=\left(1-\Psi_{x_{1} \rightarrow y_{d}}\right)^{30}
$$

where $\Psi_{x(l) \rightarrow y(d)}$ is the daily mortality rate. The variance was computed by the delta method as:

$$
\widehat{\operatorname{var}}\left[S_{30-\text { day }}\right]=\left(30\left(1-\Psi_{x_{1} \rightarrow y_{d}}\right)^{29}\right)^{2} \widehat{\operatorname{var}}\left[\Psi_{x_{1} \rightarrow y_{d}}\right]
$$

\section{RESULTS}

A total of 153 parental adults were monitored from May to August. There were 20 nesting on grassland, 66 on agricultural fields, and 67 on prairie dog colonies. Low numbers on grassland may reflect low nesting effort on this habitat, perhaps resulting from a lack of suitable grassland habitat for plover breeding. I confirmed mortality for 11 parental adults, one on agricultural fields, seven on prairie dog habitat, and three on grassland, by locating whole or partial carcasses. In the same year, predation by Great Horned Owl, Bubo virginianus, is suspected in three confirmed mortalities on prairie dog colonies. The owl was often observed in the area and feather plucks were located along with the 
transmitter. As a result of the condition in which the transmitters were found, e.g., broken/curled antennas, and observation of remains' legs, mammal predation is suspected in three mortalities, one on each of the three habitats. Cause of mortality of the remaining five adults is unknown. Of the confirmed mortalities, seven adults stayed on their nest habitat, and four adults moved to a different habitat. The radio transmitter was found but fate could not be confirmed for 19 individuals.

There were more parental males $(n=79)$ than females $(n=48)$ and this pattern did not differ by habitat (agricultural fields: males $[n=37]$, females $[n=20]$; prairie dog: males $[n=30]$, females $[n=$ 24]; grassland: males $[n=12]$, females $[n=4])$. The sex of 26 parents was unknown because of the lack of a DNA sample. At one to five days prior to hatching date, females $($ mean $=102.3 \mathrm{~g}, \mathrm{SD}=7.8)$ weighed more than males (mean $=98.8 \mathrm{~g}, \mathrm{SD}=$ 6.98 ). By habitat, females weighed more than males on agricultural fields and prairie dog colonies, but not grassland (Fig. 2). The latter may be the result of small sample size $(n=4)$ and one of these females weighed $85.1 \mathrm{~g}$, the lowest weight recorded for females during the study.

Of the 153 parental adults, 38 (25\%) moved off the nest habitat to a different habitat. They averaged 2.79 movements $(\mathrm{SD}=2.12)$ between different habitats but $29(76 \%)$ of them were observed more often on their nest habitat than the other habitats. Average age of chicks when parents first decided to lead their young to a different habitat was slightly older in 2005 (9.25 days post-hatch, $\mathrm{SD}=7.21)$ than in 2004 (4.67 days post-hatch, $\mathrm{SD}=5.40$ ) and 2006 (4.88 days post-hatch, $\mathrm{SD}=4.65)$.

The model selection criterion suggested that daily mortality rates of parental Mountain Plovers was not influenced by the sex of the adult, parental weight at hatching, or habitat, however movement was influenced by habitat (Table 1). Although the third and fourth best models suggested some evidence of an effect of habitat on parental mortality, the strong effect of habitat on movement is likely the factor contributing to the ranking of these two models (Table1). The logic of this statement is supported by two results. First, the four models that contained an effect of habitat on movement, $\Psi_{x(l) \rightarrow y(l)}$, had the lowest $\Delta \mathrm{AIC}_{\mathrm{c}}$ and contained most of the $w_{i}$ (Table 1). Models without the effect of habitat on $\Psi_{x(l) \rightarrow y(l)}$ had no support as best approximating model, i.e., $\Delta \mathrm{AIC}_{\mathrm{c}}=\geq 4, w_{i}=$
0.00. Second, the standard error, SE, of the $b$ coefficients for both grassland $\left(\mathrm{b}_{\text {grassland }}=0.2345\right.$, $\mathrm{SE}=0.5726, \mathrm{CI}=-0.8878,1.3568)$ and agricultural fields $\left(\mathrm{b}_{\text {agfields }}=-0.4592, \mathrm{SE}=0.4354, \mathrm{CI}=-1.3126\right.$, 0.3943 ) are larger than the corresponding point estimate and the $95 \%$ confidence interval for both estimates overlaps zero, further suggesting no differences in mortality between the three habitats.

The estimate for daily mortality from the top model was 0.0037 ( $\mathrm{SE}=0.0007, \mathrm{CI}=0.0026,0.0053)$. Using this value, survival of parental adults during the 30-day chick-rearing period is 0.8943 ( $\mathrm{SE}=$ $0.0187, \mathrm{CI}=0.8512,0.9255)$. Fidelity was 1.000 $(\mathrm{SE}=0.0011, \mathrm{CI}=0.0041,1.000)$. Resighting probability for live parents was 0.9430 ( $\mathrm{SE}=$ $0.0063, \mathrm{CI}=0.9292,0.9542)$ and dead recovery was $0.5312(\mathrm{SE}=0.1323, \mathrm{CI}=0.2857,0.7625)$. Estimates of daily movement probabilities suggest that parental Mountain Plover adults on grassland were more likely to leave grassland $(\Psi$ (l) $=0.0641, \mathrm{SE}=0.0101, \mathrm{CI}=0.0470,0.0870)$ than agricultural fields $\left(\Psi_{\text {agfields }(l) \rightarrow y(l)}=0.0116, \mathrm{SE}=\right.$ $0.0020, \mathrm{CI}=0.0081,0.0165)$ or prairie dog habitat

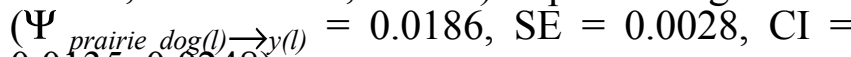
$0.0135,0.0248)$.

\section{DISCUSSION}

Reproduction may directly or indirectly pose mortality risks to parental adults. The mechanisms through which mortality risks might compromise reproductive success may differ between reproductive stages, and studies investigating mortality of adults should consider each stage separately. Many reproducing shorebirds are more vulnerable during the post-hatching period than during incubation. We estimated mortality and examined different factors potentially influencing mortality of parental Mountain Plovers during the post-hatching period. The results did not suggest an effect of habitat, sex, or body mass on mortality. Habitat did influence parental movements. Parental Mountain Plovers were more likely to leave native habitat, i.e., grassland, and stay on a highly altered habitat, i.e., agricultural fields. The reasons for this pattern could not be determined. Density and biomass of prey resources between the three habitats did not influence survival of Mountain Plover chicks or brood movement (Dreitz 2009). Uneven predation pressure between the habitats may be influencing parental movements and deserves further investigation. 
Fig. 2. Body mass of male and female parental Mountain Plovers (Charadrius montanus) that were monitored from 2004-2006. Body mass was obtained at or near hatching. The solid line represents the median, the box represents the lower $25 \%$ and upper $75 \%$ quartiles, the dashed line and dots represent outliers in the dataset.
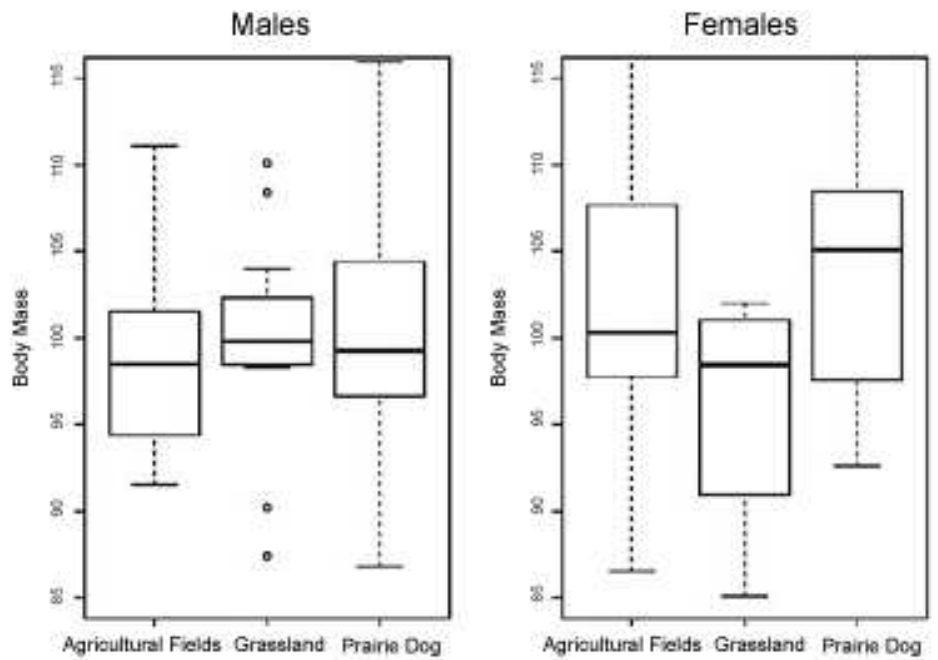

The data did not suggest that habitat influenced mortality of parental Mountain Plovers. Habitats do vary over time in the quality of food resources and predation pressure. Parental Mountain Plovers have likely adapted to dealing with these changes by moving with their young to different habitats. The influence of habitat may be more important for chicks or young Mountain Plovers (Dreitz 2009). Young birds are not as proficient at foraging as adults, and younger birds are more vulnerable to predation, especially prior to fledging age because of the lack of ability to fly.

We did not find differences in the costs associated with post-hatching care between males and females. Annual estimates of adult survival in Montana show weak evidence of a sex effect with males having slightly higher survival than females (Dinsmore 2008). The uniparental behavior of Mountain Plovers may contribute to energetic costs being more similar between males and females. Once a clutch is laid, one adult commits to tending to the eggs, and care of eggs and young is not shared between the two parents. Differences in reproductive expenditures occur prior to this in which males have a greater role in courtship and territory defense (Graul 1973), whereas females are responsible for production of eggs. Additionally, the ratio of males to females on nests in this study was 1.6:1. The post-hatching parental adults that were included in this study were those adults that successfully hatched chicks from the 512 nests located and monitored. The sex ratio for these 512 nests, including those that successfully hatched, was similar (1.5 males: 1 female).

Even though parental care may deteriorate the physical condition of adults and have survival costs (Owens \& Bennett 1994), the results did not suggest that body mass influenced parental survival. Many adult birds lose mass during the breeding cycle (e. g., Baldwin and Kendeigh 1938, Norberg 1981, Moreno 1989). How much mass is lost is influenced by the breeding stage and the sex of the adult (Norberg 1981, Weston and Elgar 2005). Female shorebirds lay some of the largest eggs in relation to their body size (Rahn et al. 1975) with the greatest and most drastic change in body mass occurring at laying. On the other hand, it is during the courtship period that adult males experience the greatest loss of mass but the change is less drastic than females. Instead of examining body mass at a particular stage in the breeding cycle, as I did at or near hatching, changes in body mass from the initiation of the breeding period to the time young fledge may have more of an influence on parental survival. 
In the one-month period after hatching, parental survival of Mountain Plovers was 0.8943 . The only other within-year survival estimate reported for this species is during the winter 1 Nov to 15 Mar, a 4.5 month period, in California as 0.9474 (Knopf and Rupert 1995). Crude extrapolations of these estimates over an annual cycle suggest that population declines may be acting more on reproduction (Knopf and Rupert 1999) than winter stages (Knopf and Rupert 1995, Wunder and Knopf 2003). Information on survival during the incubation period, along with survival of nonbreeding individuals during the breeding period, is needed to support this hypothesis.

The findings from this study provide a better basis for understanding the population dynamics of Mountain Plovers throughout their annual cycle. They underscore the need for knowledge about population dynamics to realize the full conservation value of survival estimates. Mortality risks in birds and the factors acting on mortality have important spatial components. Factors such as weather conditions, predation pressure, and habitat fragmentation might vary from region to region and their potential influences on demographic parameters are sometimes difficult to detect, in particular in highly mobile species whose individuals move over a wide geographic range.

Historically, grassland birds lived in a structurally diverse ecosystem which evolved under varying gradients of temperature and seasonal precipitation as well as combinations of both grazing and fire disturbances. The grasslands of today are a collection of homogenous grassland fragments interspersed with agricultural fields (Smith and Lomolino 2004). Understanding the associations with today's grassland habitats and the dynamics of Mountain Plovers, along with other grassland birds, will remain topics of importance. Conservation plans and effective management for Mountain Plovers and other grassland birds will require three general types of data: (1) estimates of habitatspecific demography for both adults and juveniles; (2) measures of habitat availability on breeding grounds, at migratory stopover sites, and on wintering grounds; and (3) predictions of how habitat distributions could change in the future. Until we have these data, concluding that Mountain Plovers, or any other grassland bird species, are limited predominately by events in either overwinter, breeding, or during migration are premature.
Responses to this article can be read online at:

http://www.ace-eco.org/vol5/iss 1/art4/responses/

\section{Acknowledgments:}

I sincerely thank the private landowners throughout central eastern Colorado who provided access to their lands. Numerous individuals assisted with collection of field data. P. M. Lukacs provided statistical assistance. I thank G. C. White for modifying program MARK to allow for missing values in the multistate model. The care and handling of animals was approved by the Colorado Division of Wildlife Animal Care and Use Committee (\#2-2004). Financial and logistical support was provided by the Colorado Division of Wildlife. M. Alldredge, M. Rice, B. Sandercock, M.

Wunder, and two anonymous reviewers provided useful comments on early drafts of this manuscript.

\section{LITERATURE CITED}

Akaike, H. 1973. Information theory as an extension of the maximum likelihood principle. Pages 267-281 in B. N. Petrov and F. Csaki, editors. Second International Symposium on Information Theory. Akademiai Kiado, Budapest, Hungary.

Askins, R. A., F. Chávez-Ramírez, B. C. Dale, C. A. Haas, J. R. Herkert, F. L. Knopf, and P. D. Vickery. 2007. Conservation of grassland birds in North America: understanding ecological processes in different regions. Ornithological Monographs 64:1-46.

Baldwin, S. P., and S. C. Kendeigh. 1938. Variations in the weight of birds. Auk 55: 416-467.

Blohm, R. J., R. E. Reynolds, J. P. Bladen, J. D. Nichols, J. E. Hines, K. H. Pollock, and R. T. Eberhardt. 1987. Mallard mortality rates on key breeding and wintering areas. Transactions of the North American Wildlife and Natural Resources Conference 52:246-257.

Bond, J. C., S. A. Iverson, N. B. MacCallum, C. M. Smith, H. J. Bruner, and D. Esler. 2009. Variation in breeding season survival of female harlequin ducks. Journal of Wildlife Management 73:965-972. 
Brownie, C., J. E. Hines, J. D. Nichols, K. H. Pollock, and J. B. Hestbeck. 1993. Capturerecapture studies for multiple strata including nonMarkovian transitions. Biometrics 49:1173-1187.

Brunton, D. H. 1990. The effects of nesting stage, sex, and type of predator on parental defense by Killdeer (Charadrius vociferous): testing models of avian parental defense. Behavioral Ecology and Sociobiology 26:181-190.

Burnham, K. P., and D. R.Anderson. 2002. Model Selection and multimodel inference: a practical information-theoretic approach. Second edition. Springer, New York, New York, USA.

Cormack, R. M. 1964. Estimates of survival from the sighting of marked animals. Biometrics 51:429-438.

Dinsmore, S. J. 2008. Influence of drought on annual survival of the Mountain Plover in Montana. Condor 110:45-54.

Duriez, O., S. A. Sæther, B. J. Ens, R. Choquet, R. Pradel, R. H. D. Lambeck, and M. Klaassen. 2009. Estimating survival and movements using both live and dead recoveries: a case study of oystercatchers confronted with habitat change. Journal of Applied Ecology 46:144-153.

Dreitz, V. J. 2009. Parental behavior of a precocial species: implications for juvenile survival. Journal of Applied Ecology 46:870-878.

Dreitz, V. J., and F. L. Knopf. 2007. Mountain Plovers and the politics of research on private lands. BioScience 57:681-687.

Dreitz, V. J., M. B. Wunder, and F. L. Knopf. 2005. Comparative movements and home ranges of Mountain Plover broods in three Colorado landscapes. Wilson Bulletin 117:128-132.

Gauthier, G., R. Pradel, S. Menu, and J.-D. Lebreton. 2001. Seasonal survival of Greater Snow Geese and effect of hunting under dependence in sighting probability. Ecology 82:3105-3119.

Graul, W. D. 1973. Adaptive aspects of the Mountain Plover social system. The Living Bird 12:69-94.
Graul, W. D. 1975. Breeding biology of the Mountain Plover. Wilson Bulletin 87:6-31.

Hagan, C. A., J. C. Pitman, B. K. Sandercock, R. J. Robel, and R. D. Applegate. 2007. Age-specific survival and probable causes of mortality in female Lesser Prairie-Chickens. Journal of Wildlife Management 71:518-525.

Hartke, K. M., J. B. Grand, G. R. Hepp, and T. H. Folk. 2006. Sources of variation in survival of breeding female wood ducks. Condor 108:201-210.

Hestbeck, J. B., J. D. Nichols, and R. Malecki. 1991. Estimates of movement and site fidelity using mark-resight data of wintering Canada geese. Ecology 72:523-533.

Hurvich, C. M., and C.-L. Tsai. 1989. Regression and time series model selection in sample samples. Biometrika 76:297-307.

Johannson, O., and D. Blomqvist. 1996. Habitat selection and diet of lapwing Vanellus vanellus chicks on coastal farmland in S.W. Sweden. Journal of Applied Ecology 33:1030-1040.

Jolly, G. M. 1965. Explicit estimates from capturerecapture data with both death and immigrationstochastic models. Biometrika 64:225-247.

Knopf, F. L., and J. R. Rupert. 1995. Habits and habitats of Mountain Plovers in California. Condor 97:743-751.

Knopf, F. L., and J. R. Rupert. 1999. Use of cultivated fields by breeding Mountain Plovers in Colorado. Studies in Avian Biology 19:81-86.

Knopf, F. L., and M. B. Wunder. 2006. Mountain Plover (Charadrius montanus). Number 211 in A. Poole and F. Gill, editors. The Birds of North America. The Academy of Natural Sciences, Philadelphia, Pennsylvania, and the American Ornithologists' Union, Washington, D.C., USA.

Lebreton, J. D., T. Almeras, and R. Pradel. 1999. Competing events, mixture of information and multistratum recapture models. Bird Study 46S: S32-38.

Lengyel, S. 2006. Spatial differences in breeding success in the Pied Avocet Recurvirostra avosetta: 
effects of habitat on hatching success and chick survival. Journal of Avian Biology 37:381-395.

Liker, A., and T. Székely. 2005. Mortality costs of sexual selection and parental care in natural populations of birds. Evolution 59:890-897.

Madsen, J., M. Frederiksen, and B. Ganter. 2002. Trends in annual and seasonal survival of Pinkfooted Geese Anser brachyrhynchus. Ibis 144:218-226.

Moreno, J. 1989. Strategies of mass change in breeding birds. Biological Journal of the Linnean Society 37:297-310.

Norberg, R. A. 1981. Temporary weight decrease in breeding birds may result in more fledged young. American Naturalist 118:838-850.

Owen, M., and J. M. Black. 1991. The importance of migration mortality in non-passerine birds. Pages 360-372 in C. M. Perrins, J. -D. Lebreton, and G. J. M. Hirons, editors. Bird population studies. Oxford University Press, Oxford, UK.

Owens, I. P. F., and P. M. Bennett. 1994. Mortality costs of parental care and sexual dimorphism in birds. Proceedings of the Royal Society of London B: Biological Sciences 257:1-8.

Pearce-Higgins, J. W., and D. W. Yalden. 2004. Habitat selection, diet, arthropod availability and growth of a moorland wader: the ecology of European Golden Plover Pluvialis apricaria chicks. Ibis 146:335-346.

Rahn, H., C. V. Paganelli, and A. Ar. 1975. Relation of avian egg weight to body-weight. Auk 92:750-765.

Schwarz, C. J., J. F. Schweigert, and A. N. Arnason. 1993. Estimating migration rates using tag-recovery data. Biometrics 49:177-193.

Seber, G. A. F. 1965. A note on the multiple recapture census. Biometrika 52:249-259.

Smith, G. A., and M. V. Lomolino. 2004. Blacktailed prairie dogs and the structure of avian communities on the shortgrass plains. Oecologia 138:592-602.

Székely, T. 1996. Brood desertion in Kentish Plover Charadrius alexandrinus: an experimental test of parental quality and remating opportunities. Ibis 138:749-755.

Tipton, H. C., P. F. Doherty, Jr. and V. J. Dreitz. 2009. Abundance and density of Mountain Plover and Burrowing Owl in Eastern Colorado. Auk 126:493-499.

Ward, D. H., E. A. Rexstad, J. S. Sedinger, M. S. Lindberg, and N. K. Dawe. 1997. Seasonal and annual survival of adult Pacific brant. Journal of Wildlife Management 61:773-781.

Weston, M. A., and M. A. Elgar. 2005. Parental care in Hooded Plovers (Thinornis rubricollis). Emu 105:283-292.

White, G. C., and K. P. Burnham. 1999. Program MARK: Survival estimation from populations of marked animals. Bird Study 46 (Supplement):120-138.

Wunder, M. B., and F. L. Knopf. 2003. Imperial Valley agriculture is critical to wintering Mountain Plovers. Journal of Field Ornithology 74:74-80. 